\title{
The expression and function of epithelial membrane protein 1 in laryngeal carcinoma
}

\author{
HONG LI ${ }^{1}$, XIAOWEN ZHANG ${ }^{2}$, XUEJUN JIANG ${ }^{3}$ and $\mathrm{XU} \mathrm{JI}^{3}$ \\ ${ }^{1}$ Department of Otorhinolaryngology Head and Neck Surgery, The Fourth Affiliated Hospital of China Medical University, \\ Shenyang, Liaoning 110032; ${ }^{2}$ Department of Genetics, Teaching and Learning Office, China Medical University, Shenyang, \\ Liaoning; ${ }^{3}$ Department of Otolaryngology, The First Affiliated Hospital of China Medical University, \\ Shenyang, Liaoning 110001, P.R. China
}

Received July 7, 2016; Accepted November 17, 2016

DOI: $10.3892 /$ ijo.2016.3782

\begin{abstract}
In this study, we compared the expression of epithelial membrane protein 1 (EMP1) on the steady-state mRNA level (by quantitative real-time PCR) and on the protein level (by western immunoblot and immunohistochemistry) in 51 pairs of laryngeal carcinoma tissues and matched cancer-free peritumor tissues, and we analyzed the correlation between EMP1 expression and different clinicopathological factors. Furthermore, we ectopically expressed EMP1 in human laryngeal carcinoma Hep-2 cells and examined the effects on cell viability, apoptosis, colonogenicity, and motility, by MTT assay, flow cytometry, colony formation assay and Transwell migration assay, respectively. EMP1 expression (on both the mRNA and protein levels) was significantly lower in the cancer tissues than in matched peritumor tissues $(\mathrm{P}<0.05)$. In laryngeal cancers, the level of EMP1 protein was correlated with histological grade $(\mathrm{P}<0.05)$, but not with age, gender, clinical stage, cancer subtype or lymph node metastasis $(\mathrm{P}>0.05)$. Functionally, ectopic expression of EMP1 in Hep-2 cells significantly reduced cell viability, colony formation, and migration, but enhanced apoptosis. Therefore, EMP1 is a tumor suppressor in laryngeal carcinoma. Boosting EMP1 expression in laryngeal carcinoma initiates multiple anticancer phenotypes and thus presents a promising therapeutic strategy for laryngeal cancer.
\end{abstract}

\section{Introduction}

Laryngeal carcinoma is the second most malignant tumor of the upper respiratory tract (after lung cancer), accounting

Correspondence to: Dr Xuejun Jiang or Dr Xu Ji, Department of Otolaryngology, The First Affiliated Hospital of China Medical University, Shenyang, Liaoning 110001, P.R. China

E-mail: djiangxj@163.com

E-mail: hljanterior@163.com

Key words: epithelial membrane protein 1, laryngeal carcinoma, tumor suppressor gene, viability, colony formation, migration for $2.4 \%$ of all new cases of malignancy worldwide annually $(1,2)$. According to the regions affected, laryngeal carcinoma is divided into supraglottis, glottis and subglottis carcinoma. Based on histology, $>95 \%$ of laryngeal carcinomas are squamous cell carcinoma (3). Surgery (with concomitant chemotherapy) and radiotherapy represent the mainstream treatments for laryngeal cancer. Function preservation has significant weight in the selection of therapeutic approaches. Therefore, there is a pressing need to identify new biological indicators for predicting prognosis, help selecting treatment strategies, and facilitate the development of novel therapeutic approaches.

Several studies have shown the downregulation of the epithelial membrane protein 1 (EMP1), also known as RAP, CL-20 and B4B, in head and neck carcinomas (4-7). EMP1 was first cloned from the fetal rat intestinal cDNA library and is considered to form a gene family with the peripheral myelin protein and the lens-specific membrane protein 20 , due to the sequence homology of these three proteins (8). The EMP1 gene is located on human chromosome 12p12.3 $(9,10)$. It encodes a glycoprotein of 157 amino acids that contains four transmembrane domains (11). As indicated by its name, EMP1 is primarily expressed in squamous epithelium and presents different levels of expression in a variety of normal tissues, such as the gastrointestinal tract of the gastric bottom, ileum and colon (8), liver (12) and prostate (13). EMP1 is associated with a collection of biological activities, including cell proliferation, differentiation, and apoptosis (14). It is therefore not surprising that EMP1 may play a role in cancer development. However, the significance of EMP1 in cancer seems to vary with different tumor types: the overexpression of EMP1 was detected in leiomyoma uteri (15), lung cancer (16), leukemia (17), and brain glioma (18), whereas the downregulation of EMP1 was reported in esophageal carcinoma (19), gastric cancer (20), prostate cancer (21), oral squamous cell carcinoma (22), breast cancer (23) and nasopharyngeal carcinoma (24).

No studies have systemically examined the status and explored the biological activities of EMP1 in laryngeal cancer or come close to doing this. We tackled this task in this study. By comparing EMP1 expression in 51 laryngeal carcinoma tissues with that of matched cancer-free peritumor tissues, we 
assessed the expression and clinical correlation of EMP1 in laryngeal carcinoma. Furthermore, using a gain-of-function approach, we examined the biological activities of EMP1 in laryngeal cancer cells.

\section{Materials and methods}

Human tissue samples and cell lines. This study was approved by the Institutional Bioethics Committee of China Medical University (Shenyang, China) and informed consent was obtained from all participating individuals. A total of 51 pairs of samples, including a tumor sample (T) and a matched, cancer-free peritumor tissue sample $(\mathrm{N})$, were examined in this study. All tissues were obtained from patients diagnosed with laryngeal carcinoma and receiving surgery (including partial laryngectomy in 29 patients and total laryngectomy in 22) at the First Hospital of China Medical University from 2011 to 2012. Immediately after surgical removal from the patients, 24 pairs of tissue samples were snap-frozen in liquid nitrogen and then transferred to $-80^{\circ} \mathrm{C}$ until further use (for western immunoblot); another 27 pairs of tissue samples were fixed in formalin before being embedded into paraffin and processed into $4-\mu \mathrm{m}$ thick sections (for immunohistochemistry).

Human laryngeal carcinoma cell line,Hep-2, was purchased from the Cell Bank, Chinese Academy of Sciences (Shanghai, China) and cultured in RPMI-1640 medium (Gibco, Carlsbad, CA, USA) containing 10\% fetal bovine serum (FBS; HyClone, Logan, UT, USA).

Immunohistochemical (IHC) staining and scoring. IHC staining was performed using the IHC staining kit (Maxim, Fuzhou, China), following the manufacturer's instructions. Briefly, the tissue sections were blocked with $\mathrm{H}_{2} \mathrm{O}_{2}$ (to block endogenous peroxidase) followed by nonimmune serum (reagent A) for $20 \mathrm{~min}$, and then incubated with mouse antihuman EMP1 polyclonal antibody (Abnova, Taiwan, China) at $4^{\circ} \mathrm{C}$ overnight. After being washed with phosphate-buffered saline (PBS) 3 times, the sections were incubated with biotinylated secondary antibody (reagent B) at room temperature for $15 \mathrm{~min}$, followed by streptavidin-horseradish peroxidase (reagent $\mathrm{C}$ ) for $15 \mathrm{~min}$. The signals were detected using 3,3'-diaminobenzidine tetrahydrochloride (DAB; Maxim) and counter stained with hematoxylin.

The tissue sections were scored by two independent pathologists blinded to the study, as detailed below. The "positive rate' $(\mathrm{P})$ was defined as follows: 0 means $<10 \%$ of the tissues showed positive staining; $1,10-25 \% ; 2,26-50 \% ; 3,51-75 \%$; and 4, 76-100\%. The 'intensity of staining' (I) was defined as: 0 indicated negative staining; 1 , light yellow; 2 , brown; and 3 , dark brown. The total staining score $(\mathrm{S})$ was calculated as $\mathrm{P} \times \mathrm{I}$.

Reverse transcription quantitative real-time PCR (RT-PCR). Total RNA was isolated from frozen tissues ( 100 mg each) using TRIzol reagent (Invitrogen, Carlsbad, CA, USA) following the manufacturer's instructions. Reverse transcription into cDNA was then performed on total RNA, using the Reverse Transcription system (A3500; Promega, Madison, WI, USA) per the manufacturer's instructions. Real-time PCR was performed using the following primers: EMP1 forward, 5'-AGGGAATACA TGGTTTACTCCA-3' and reverse, 5'-AGAGAGATTGGCCAG CAAAA-3'; GAPDH (internal control), forward, 5'-ACGGAT TTGGTCGTATTGGG-3', reverse, 5'-CGCTCCTGGAAGATG GTGAT-3'. The thermal cycling conditions were $95^{\circ} \mathrm{C}$ for $30 \mathrm{sec}$, followed by 40 cycles of $95^{\circ} \mathrm{C}$ for $5 \mathrm{sec}$ and $60^{\circ} \mathrm{C}$ for $34 \mathrm{sec}$.

Western blot analysis. To measure the protein level of EMP1 in tissues, 24 pairs of samples ( $200 \mathrm{mg}$ each) were individually packaged in sterilized tinfoil, frozen in liquid nitrogen for $10 \mathrm{~min}$, and broken into powder with a pulverizer. The tissue powder was then homogenized in PBS at $0^{\circ} \mathrm{C}$ followed by digestion in lysis buffer on ice for $30 \mathrm{~min}$. After centrifugation at $14,000 \mathrm{x}$ f for $5 \mathrm{~min}$, protein-containing supernatant was collected and the protein concentration was measured using the BCA protein assay kit (Beyotime, Jiangsu, China), according to the manufacturer's instructions. A total of $80 \mu \mathrm{g}$ protein from each sample was separated on SDS-PAGE gel, transferred onto PVDF membrane, blocked in Tris- $\mathrm{HCl}$ and Tween-20 (TBST) buffer containing 5\% fat-free milk, and incubated with either rabbit anti-human EMP1 antibody (1:500; Abcam, Cambridge, MA, USA) or anti- $\beta$-actin antibody (internal control; Beyotime) at $4^{\circ} \mathrm{C}$ overnight. After being washed with TBST 3 times (5 min each), the membrane was incubated with a horseradish peroxidase (HRP)-conjugated goat anti-rabbit-IgG $(1: 2,000$, ZSGB-Bio Origene, Beijing, China) at $37^{\circ} \mathrm{C}$ for $90 \mathrm{~min}$. Detection was achieved using enhanced chemiluminescence (ECL) substrate (Thermo Fisher Scientific, Waltham, MA, USA) by ECL, and the images were acquired and quantified by the Gel Imaging system (Chishun, Nanjing, China).

Transfection. For transient transfection of EMP1 into Hep-2 cells, the mammalian expression vector pcDNA3.1 expressing no proteins (control, pcDNA3.1-empty) and that expressing human EMP1 (pcDNA3.1-EMP1; GenScript, Nanjing, China) were transfected into Hep-2 cells using Lipofectamine 2000 (Invitrogen), according to the manufacturer's instructions.

MTT assay. Hep-2 cells in log phase were seeded into a 96-well plate at $5 \times 10^{3} / \mathrm{ml}$, with each condition set up in quintuplicate. Then cells were transfected with either pcDNA3.1-empty or pcDNA3.1-EMP1 for 24, 48, 72, 96 or $120 \mathrm{~h}$. Then MTT ( $5 \mathrm{mg} / \mathrm{ml}, 10 \mu \mathrm{l} /$ well; Sigma, St. Louis, MO, USA) reagent was added into each well and incubated with cells for a further $4 \mathrm{~h}$, after which, DMSO (150 $\mu \mathrm{l} /$ well) was added to the cells and the plate was gently shaken for $15 \mathrm{~min}$. Absorbance was measured at $490 \mathrm{~nm}$.

Colony formation assay. Colony formation assay was performed as previously described (25). Briefly, at $24 \mathrm{~h}$, after transfecting Hep-2 cells with either pcDNA3.1-empty or pcDNA3.1-EMP1, 4,000 cells were seeded into the 6-well tissue culture plate and cultured at $37^{\circ} \mathrm{C}$ for two weeks. The colonies were fixed in $95 \%$ ethanol, stained with crystal violet $(0.1 \% \mathrm{w} / \mathrm{v})$, and counted under a microscope.

Transwell migration assay. For the Transwell migration assay, Hep- 2 cells at $24 \mathrm{~h}$ after transfection $\left(8 \times 10^{4} / \mathrm{ml}\right)$ were seeded into the upper chamber of the Transwell insert (pore size $8 \mu \mathrm{m}$; Corning, Lowell, MA, USA). RPMI-1640 medium 
A

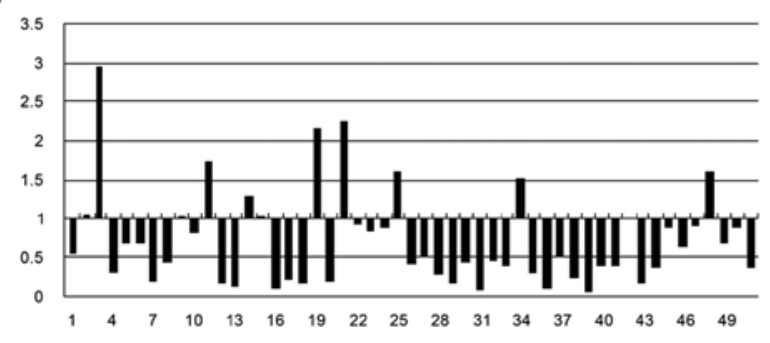

C

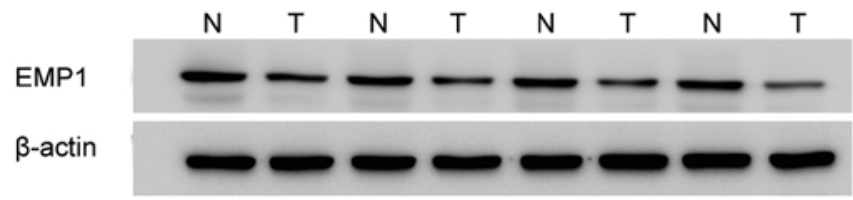

B
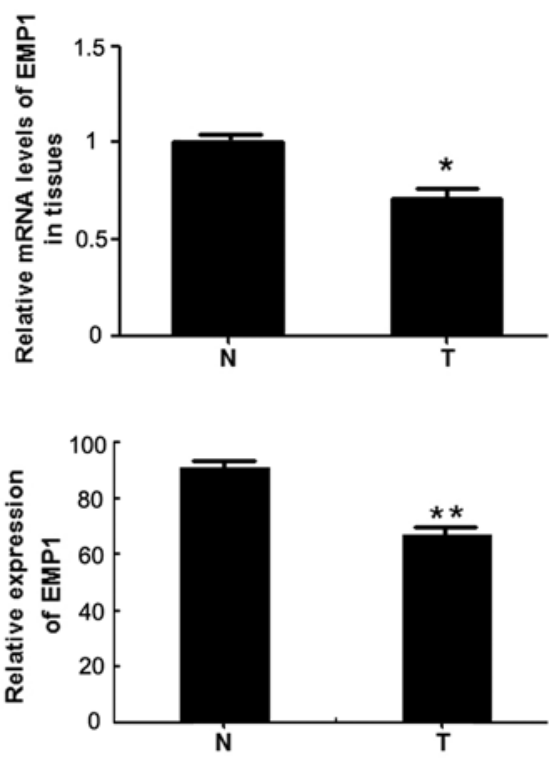

Figure 1. Epithelial membrane protein 1 (EMP1) expression in laryngeal carcinoma and peritumor tissues. (A) Steady-state mRNA level of EMP1 in 51 pairs of cancer and matched peritumor tissues was examined by quantitative RT-PCR, and presented as a ratio of the former to the latter. (B) Comparison of EMP1 mRNA in cancer tissue (T) and matched peritumor tissue normal (N) was performed using Student's t-test, with level in N sample from each pair arbitrarily defined as 1. (C) Representative western blot images of EMP1 expression in 8 pairs of T and $\mathrm{N}$ samples. Actin was determined as internal control. (D) Quantifications of EMP1 protein level in 24 pairs of $\mathrm{R}$ and $\mathrm{T}$ samples, with level in $\mathrm{R}$ sample from each pair arbitrarily defined as 1 . ${ }^{*} \mathrm{P}<0.05$ : ${ }^{* *} \mathrm{P}<0.01$, compared to the R samples.

with $10 \%$ FBS was added into the lower chamber. After $24 \mathrm{~h}$ migration at $37^{\circ} \mathrm{C}$, the insert was fixed with $10 \%$ methanol and washed 3 times with PBS. The cells remaining on the upper surface of the insert membrane were gently removed by wiping with cotton swabs. The insert was stained with hematoxylin for $40 \mathrm{sec}$, washed with PBS 3 times, and stained with eosin for 3 min. After another three washes with PBS, the cells were re-stained with hematoxylin for $30 \mathrm{sec}$. Each experimental condition was set up in quintuplicate. The migrated cells were imaged under a light microscope and the number of migrated cells was averaged from five fields (upper, lower, left, right and center) in each image.

Apoptosis assay. At $24 \mathrm{~h}$ and $48 \mathrm{~h}$ after transfection of Hep-2 cells with either pcDNA3.1-empty or pcDNA3.1-EMP1, the cells were detached with trypsin, washed with PBS 3 times, and stained with $5 \mu$ l fluorescein isothiocyanate (FITC)-conjugated Annexin $\mathrm{V}$ and $10 \mu \mathrm{l}$ propidium iodide (PI) (both from Keygen, Jiangsu, China) staining solution at room temperature for 15 min. After staining, the cells were analyzed by a FACScan flow cytometer (BD Biosciences, Franklin Lakes, NJ, USA).

Statistical analysis. All experiments were independently repeated at least 3 times. Data were presented as mean \pm SD. A $\chi^{2}$ test was used to examine the possible associations between EMP1 expression and clinicopathological factors. Student's t-test was used to compare differences between control and treatment cells. SPSS 16.0 for Windows was used for statistical analyses. $\mathrm{P}<0.05$ was considered statistically significant.

\section{Results}

EMP1 is downregulated on both the mRNA and protein level in laryngeal carcinoma tissues compared to in peritumor tissues. To assess the status of EMP1 in laryngeal carcinoma, we first compared its expression on both the steady-state mRNA and the protein levels in laryngeal carcinoma tissues to that in matched cancer-free peritumor tissues. As shown in Fig. 1A, out of the 51 sample pairs examined, in only 3 pairs was the EMP1 mRNA level more than twice as high in $\mathrm{T}$ than in $\mathrm{N}$ tissues; while in 24 pairs, the level was reduced by $>50 \%$ in the $\mathrm{T}$ sample than in the matched $\mathrm{N}$ sample. The differences between the $\mathrm{T}$ and $\mathrm{N}$ samples were statistically significant $(\mathrm{P}<0.05)$ (Fig. 1B). Consistently, the EMP1 protein was significantly lower in the $\mathrm{T}$ samples than in matched $\mathrm{N}$ samples $(\mathrm{P}<0.05)$ (Fig. 1C and D).

EMP1 expression in laryngeal carcinoma tissues correlate with histological grading. IHC in tissues revealed strong EMP1 expression in peritumor normal epithelium, predominantly on the cell membrane and in the cytoplasm (Fig. 2A, left panel), where the average total staining score $(\mathrm{S})$ was $11.60 \pm 1.26$. In contrast, EMP1 staining was markedly reduced in the matched laryngeal carcinoma tissue (Fig. 2A, right panel), which was associated with a significantly lower $\mathrm{S}$ score (7.55 \pm 3.87 ; $\mathrm{P}<0.05)$. In addition, we observed that staining of EMP1 decreased with the histological grading of the tumor, with the highest $\mathrm{S}$ appearing in well-differentiated tumors, followed by intermediately differentiated tumors, and the lowest in poorly differentiated tumors (Fig. 2B). Further correlation analysis confirmed a significant correlation between the EMP1 $\mathrm{S}$ score and pathological grade $(\mathrm{P}<0.05)$ (Table I), but did not confirm a correlation with other clinicopathological features, including age, gender, TNM stage or lymph node metastasis $(\mathrm{P}>0.05)$ (Table I)

Ectopic EMP1 expression in laryngeal carcinoma cells reduced cell viability. The significant reduction of EMP1 
A

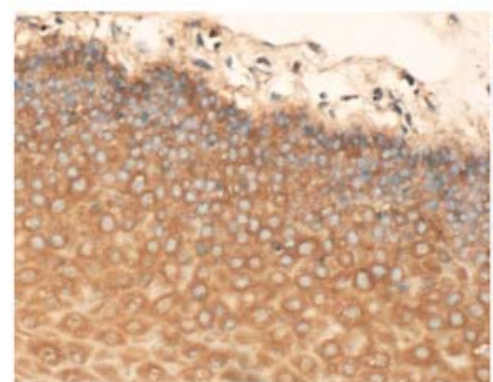

$\mathrm{N}$

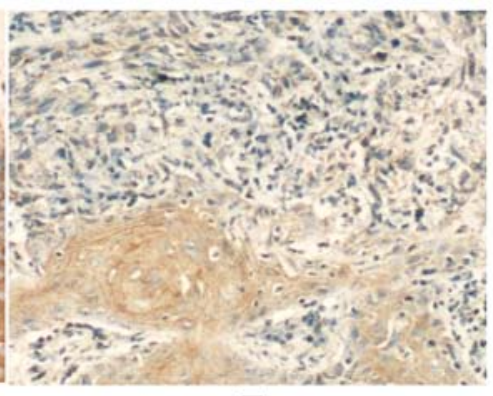

$\mathrm{T}$

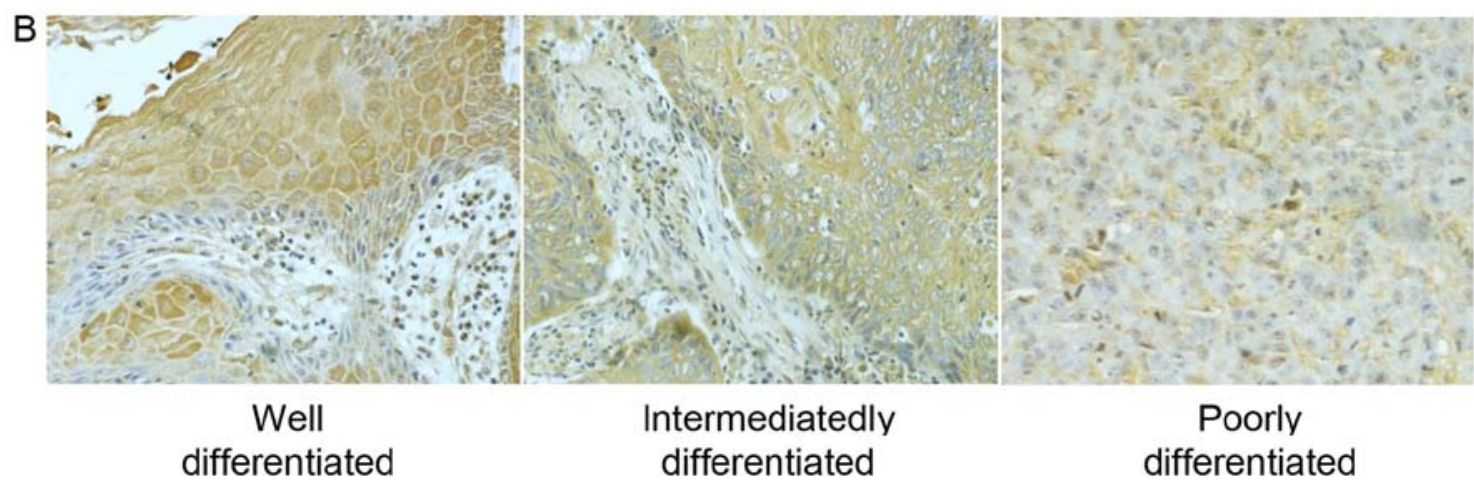

Figure 2. Epithelial membrane protein 1 (EMP1) expression was significantly lower in laryngeal carcinoma tissues than in matched cancer-free peritumor tissues, and was correlated with differentiation status of the tumor. EMP1 expression in 51 pairs of peritumor (N) and matched laryngeal carcinoma (T) samples were examined by immunohistochemistry (IHC). (A) Representative IHC images of EMP1 expression in a pair of R and T samples (x200). (B) Representative IHC images of EMP1 expression in a well-differentiated (left), an intermediately differentiated (middle), and a poorly differentiated (right) laryngeal carcinoma tissue (x200).

expression in the laryngeal carcinoma tissues compared to that in the matching peritumor laryngeal epithelia and its correlation with the differentiation status of the tumors suggest the tumor suppressor activity of EMP1. To characterize the functional significance of EMP1 in laryngeal carcinoma cells, we applied a gain-of-function approach and ectopically expressed EMP1 in laryngeal carcinoma Hep-2 cells. As shown in Fig. 3A, the transient transfection of Hep-2 cells with pcDNA3.1-EMP1 significantly boosted the expression of EMP1 in the cells, compared to cells transfected with the control vector pcDNA3.1-empty. Quantification analysis confirmed significant upregulation of EMP1 expression in pcDNA3.1-EMP1 cells compared to that in pcDNA3.1-empty cells at 24,48 and $72 \mathrm{~h}$ after transfection (Fig. 3B).

Upon the overexpression of EMP1 in Hep-2 cells, we first examined the cell viability by MTT assay. As shown in Fig. 3C, both the mock-transfected (MOCK) and pcDNA3.1-emptytransfected (control) cells presented similar viability over $120 \mathrm{~h}$ after the transfection, suggesting that the control vector did not generate an obviously unfavorable effect on cell viability. In contrast, starting from $48 \mathrm{~h}$ after transfection, viability in EMP1-expressing cells was significantly lower than in the other two groups $(\mathrm{P}<0.05)$.

EMP1 overexpression promotes the apoptosis of laryngeal carcinoma cells. Cell viability results from a balance between cell proliferation and apoptosis. The marked decrease in cell viability following EMP1 ectopic expression prompted us to assess its effect on cellular apoptosis. By staining cells with Annexin V and PI, we found that at $48 \mathrm{~h}$ after EMP1 overexpression, there was a marked increase in the percentage of
Annexin $\mathrm{V}^{+}$and $\mathrm{PI}^{+}$apoptotic cells $(11.63 \pm 0.40 \%)$, compared to cells undergoing mock transfection $(3.77 \pm 0.31 \%)$ or transfected with the control vector $(2.53 \pm 0.11 \%)(\mathrm{P}<0.05)$ (Fig. 4).

\section{EMP1 overexpression reduces colony formation and decreases} the migratory capacity of laryngeal carcinoma cells. The capability of tumor cells to generate a large number of clonogenic progeny (clonogenicity/cancer stemness) is an important feature of cancer stem cells (26). To measure the effects of EMP1 on cancer clonogenic capacity, we performed colony formation assay. EMP1 overexpression in Hep-2 cells significantly reduced the number of colonies $(675.00 \pm 43.66)$ formed, compared to mock-transfected cells $(1055.67 \pm 161.55)$ or cells transfected with the control vector $(1161.67 \pm 139.08)(\mathrm{P}<0.05)$ (Fig. 5A and B).

Migration is another important feature for cancer cells, closely related to tumor metastasis, the most lethal phenotype of cancers. Using Transwell migration assay, we revealed that EMP1 overexpression significantly reduced the number of migrated cells (13.67 $\pm 0.33 /$ field), compared to mock-transfected cells $(37.67 \pm 3.84 /$ field $)$, or cells transfected with the control vector $(34.33 \pm 2.40 /$ field; $\mathrm{P}<0.05)$ (Fig. $5 \mathrm{C}$ and $\mathrm{D}$ ).

\section{Discussion}

We systematically analyzed the expression of EMP1 on the mRNA and protein levels from 51 pairs of laryngeal carcinoma and matched cancer-free peritumor tissues. We corroborated previous findings that EMP1 is downregulated in laryngeal carcinomas (5), and its level was significantly correlated with the differentiation status of the tumor: the worse the differentiation, the lower EMP1 expression. Furthermore, we explored 
Table I. Correlations between EMP1 total staining score (S) and different clinicopathological parameters of patients.

\begin{tabular}{lcccc}
\hline \multirow{2}{*}{ Characteristics } & $\begin{array}{c}\text { No. of } \\
\text { patients }\end{array}$ & $\begin{array}{c}\text { EMP1 low } \\
\text { expression }\end{array}$ & $\begin{array}{c}\text { EMP1 high } \\
\text { expression }\end{array}$ & P-value \\
\hline
\end{tabular}

Age (years)

$\begin{array}{llrl}<60 & 22 & 9 & 13 \\ \geq 60 & 29 & 12 & 17\end{array}$

Gender

$\begin{array}{lrrrr}\text { Female } & 6 & 4 & 2 & 0.087 \\ \text { Male } & 45 & 14 & 31 & \\ \text { TNM stage } & & & & \end{array}$

$\begin{array}{lrrr}\text { I+II } & 14 & 7 & 7 \\ \text { III+IV } & 37 & 14 & 23\end{array}$

T stage

$\begin{array}{llll}1+2 & 21 & 9 & 12 \\ 3+4 & 30 & 8 & 22\end{array}$

0.973

Lymph node metastasis

\begin{tabular}{lrrrr} 
Negative & 36 & 15 & 21 & 0.912 \\
Positive & 15 & 6 & 9 & \\
$\begin{array}{l}\text { Pathological } \\
\text { grade }\end{array}$ & & & & \\
Low & 29 & 16 & 13 & 0.020 \\
High & 22 & 5 & 17 & \\
\hline
\end{tabular}

the biological activities of EMP1 in laryngeal carcinoma Hep-2 cells. We showed, for the first time, that ectopic expression EMP1 in Hep-2 cells significantly reduced cell viability, which was associated with an increase in cellular apoptosis. In addition, EMP1 inhibited the colonogenic capacity and migration of Hep-2 cells. This study supports the notion that EMP1 is a tumor suppressor in laryngeal carcinoma. Upregulating EMP1 initiates multiple anticancer effects and thus provides a promising therapeutic strategy for laryngeal carcinoma.

In an early study exploring differentially expressed genes between laryngeal carcinoma cells and matched primary normal epithelial cells, Liu et al identified 35 significantly altered genes, and EMP1 was among those downregulated in the cancer cells, presenting a 20 -fold difference between normal and cancer cells (5). Consistently, EMP1 is downregulated in other head and neck tumors $(4,27)$ all supporting tumor suppressive activity of EMP1. However, no study has systemically looked into the clinical significance of EMP1 and its biological activities in human laryngeal carcinoma. In this study, we examined 51 paired samples of laryngeal carcinomas and matched cancer-free peritumor laryngeal tissues. On the mRNA level, we showed that 24 pairs of samples presented a $>50 \%$ reduction of EMP1 mRNA in the tumor tissues compared to that in the peritumor tissues; yet three pairs showed a >2-fold increase in EMP1 mRNA in the former over in the latter. The difference in EMP1 expression on the mRNA level also translates to the protein level, an
A

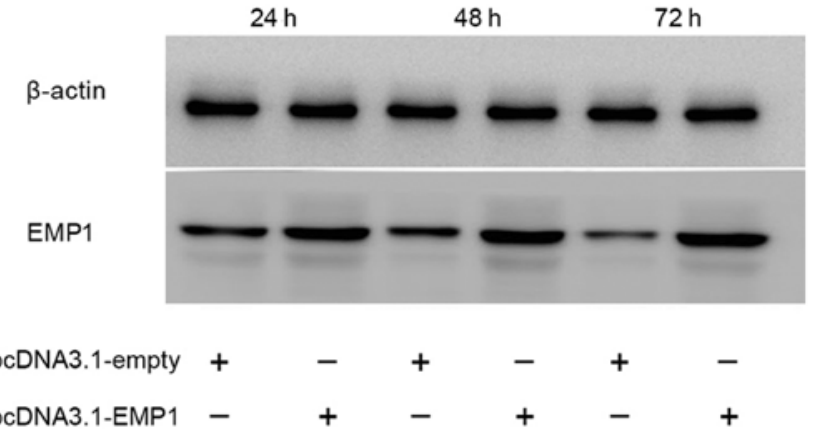

B

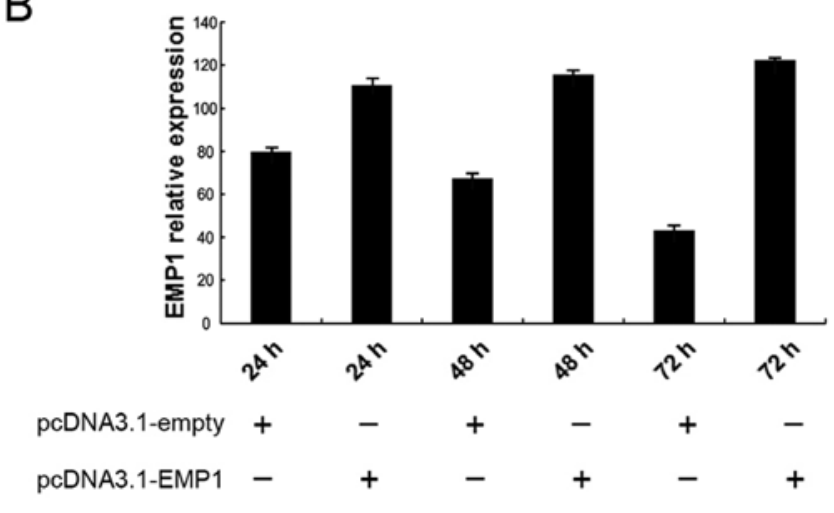

C

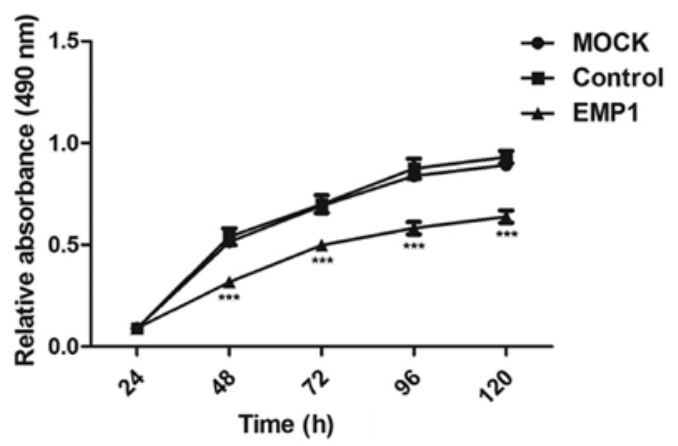

Figure 3. The effect of epithelial membrane protein 1 (EMP1) expression on cell viability in laryngeal carcinoma cells. The EMP1-expressing vector (pcDNA3.1-EMP1) or the blank control vector (pcDNA3.1-empty) was transiently transfected into Hep-2 cells. The expression of EMP1 at indicated time after transfection was determined by (A) western blotting and quantified as ratio to the signal intensity of the internal control, (B) $\beta$-actin. (C) At indicated time points after transient transfection of Hep-2 cells with mock, pcDNA3.1-empty (CTRL), or pcDNA3.1-EMP1 (EMP1), cell viability was determined by MTT assay. ${ }^{*} \mathrm{P}<0.05$ compared to the other two groups.

$\sim 50 \%$ reduction in the average protein level of EMP1 from the tumor tissues than from the peritumor tissues. In contrast to the $\sim 2$-fold difference for EMP1 expression from the present study, Liu et al reported $>20$-fold difference in EMP1 mRNA between normal and cancerous laryngeal cells (5). We noted that the study of Liu et al focused on EMP1 levels in epithelial cells, while we used the cancer and peritumor tissues, which contained other cell types in addition to epithelial cells. The presence of non-epithelial components in our source materials may dilute EMP1 signals from epithelial cells, which also suggests that EMP1 is expressed in non-epithelial components in laryngeal carcinoma. When it comes to the clinical significance of EMP1 in laryngeal carcinoma, Liu et al (5) 


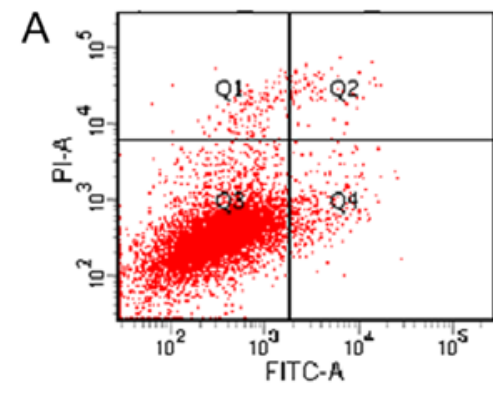

Mock

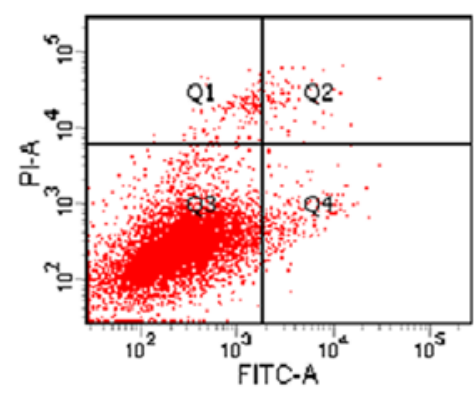

Control

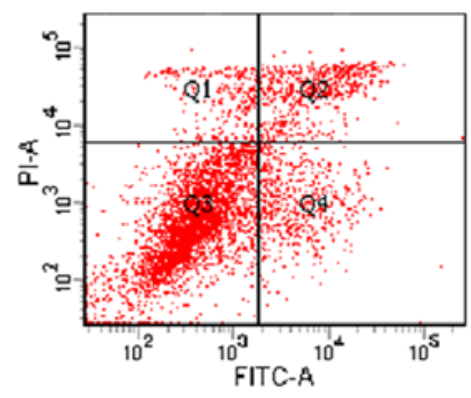

EMP1

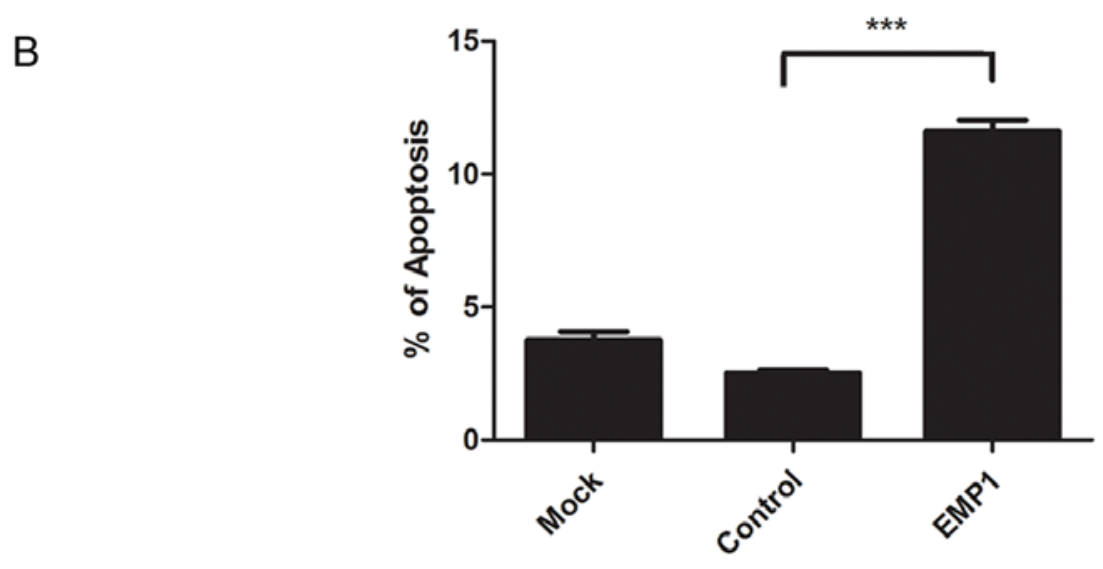

Figure 4. Epithelial membrane protein 1 (EMP1) overexpression promoted apoptosis of laryngeal carcinoma cells. At $48 \mathrm{~h}$ after transient transfection of Hep-2 cells with mock (Mock), pcDNA3.1-empty (control), or pcDNA3.1-EMP1 (EMP1), cellular apoptosis was determined by staining cells with fluorescein isothiocyanate (FITC)-conjugated Annexin V and propidium iodide (PI), and analyzed by flow cytometry. (A) Representative flow data from each group. (B) Quantitative analysis on percentage of Annexin $\mathrm{V}^{+}$and $\mathrm{PI}^{+}$apoptotic cells from at least three independent experiments. ${ }^{* * *} \mathrm{P}<0.001$ compared to other two groups.

failed to show a correlation between EMP1 expression and other clinical factors, while Zhang et al showed that in oral squamous cell carcinoma, low EMP1 expression correlated with lymphatic metastasis (7). Our analysis showed that the EMP1 level, as determined by IHC, only correlates with the differentiation status of laryngeal carcinoma, but does not correlate with the other clinicopathological parameters examined, including age, gender, clinical stages, cancer subtypes or lymph node metastasis. Although further studies involving a larger number of clinical samples should be performed on the correlation of EMP1 expression with other clinicopathological factors, including patient survival, available data suggest that EMP1 may not be a strong clinical indicator for laryngeal carcinoma. However, the findings from this study and the study of Liu et al (5) prompted us to further explore the potential biological activities of EMP1 in laryngeal carcinoma cells.

Before this study, several groups have examined the biological activities of EMP1 in different types of cancer. In breast cancer MCF-7 cells, nasopharyngeal cancer CNE2 cells, colorectal cancer SW-480 cells, gastric cancer SGC-7901 cells, and prostate cancer PC-3 cells, EMP1 transfection reduced cell survival, increased cellular apoptosis, and inhibited cell migration and invasion, which was associated with an increased expression of caspase- 9 and a decreased expression of vascular endothelial growth factor C $(20,21,23,24,28)$. Consistent with these anticancer biological activities, the expression of EMP1 was downregulated in these cancers, compared to normal tissues. In contrast, Lai et al showed that EMP1 was upregulated in non-small cell lung cancers compared to in benign lung diseases, and the overexpression of EMP1 in the lung cancer PC9 cells stimulated xenograft tumor growth in nude mice, which was associated with the activation of PI3K/AKT pathway (16). These findings suggest that EMP1 may function either as a tumor suppressor or as an oncoprotein in different human cancers. Given the relative low level of EMP1 expression in laryngeal carcinoma cells, we applied a gain-of-function approach, overexpressing EMP1, to study its effects. EMP1 expression was significantly upregulated in Hep-2 cells through transient transfection. Then we examined the biological behavior of the cancer cells, including cell viability, apoptosis, clonogenicity and migration, all closely associated with the development of laryngeal carcinoma (29). Our findings, that EMP1 reduced cell viability, increased cellular apoptosis, inhibited colonogenicity, and decreased cell migration, support tumor suppressor activities of EMP1 in laryngeal carcinoma.

Several mechanisms have been reported for the control by EMP1 of cell viability, a phenotype resulting from the balance of cell proliferation and apoptosis. For cell proliferation, when overexpressed in esophageal cancer EC9706 cells, EMP1 resulted in cell cycle arrest at $\mathrm{S}$ phase (30). In several leukemia cell lines, however, silencing EMP1 leads to G1 arrest (17). Apoptosis regulated by EMP1 has been mainly linked to the mitochondrial pathway. Li et al (31) transfected HEK293 cells with EMP-1 overexpression vectors and observed a higher activity of caspase-3 and caspase-9. Furthermore, they increased mitochondrial membrane potential and found no obvious difference in caspase- 8 activity. It is important 
A
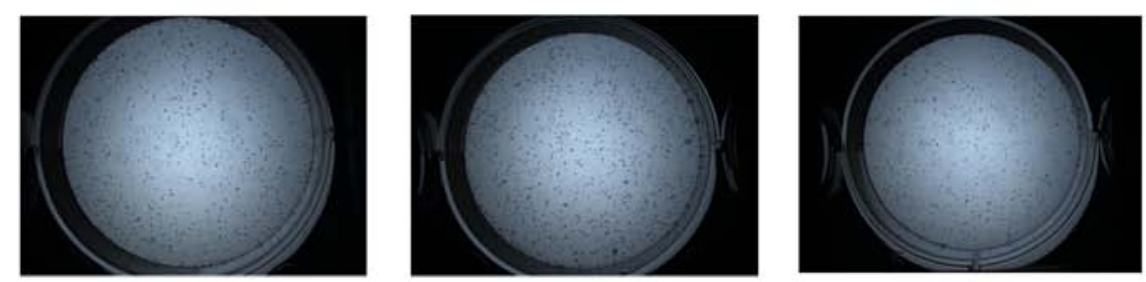

Mock

Control

EMP1

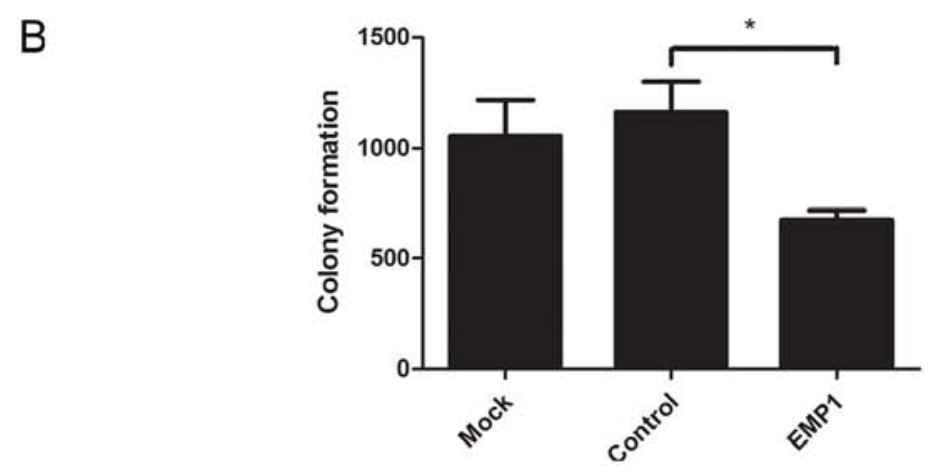

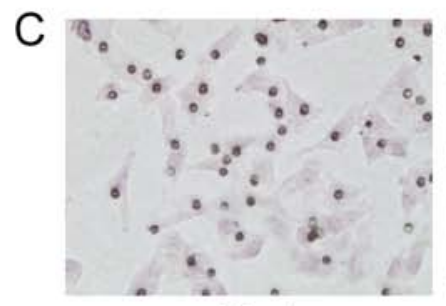

Mock

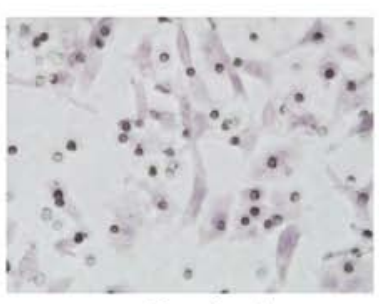

Control

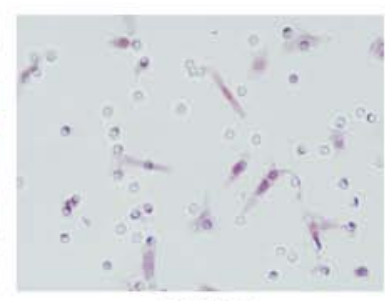

EMP1

D

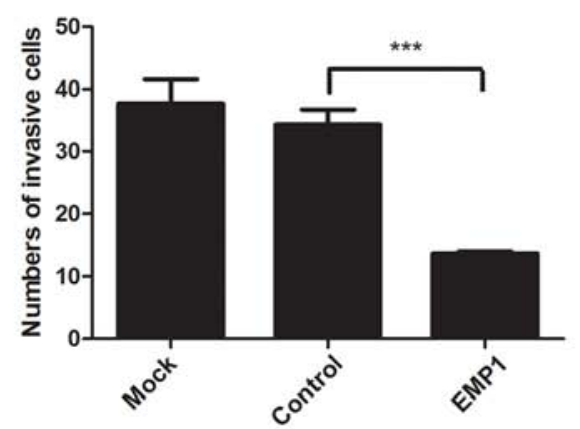

Figure 5. Epithelial membrane protein 1 (EMP1) overexpression reduced colony formation capability and decreased migratory capacity of laryngeal carcinoma cells. Colonogenic capacity of Hep-2 cells transfected with mock (Mock), pcDNA3.1-empty (CTRL), or pcDNA3.1-EMP1 (EMP1) was determined by colony formation assay. (A) Representative images of colonies formed from each group of cells. (B) Quantification of colonies from at least three independent experiments. The migratory capability of Hep-2 cells transfected with mock, pcDNA3.1-empty (CTRL), or pcDNA3.1-EMP1 (EMP1) was determined by the Transwell migration assay. (C) Representative images of migrated cells from each experimental group (x40). (B) Quantification of number of migrated cells from at least three independent experiments. ${ }^{*} \mathrm{P}<0.05$ and ${ }^{* * *} \mathrm{P}<0.001$ compared to the other two groups.

for future studies to explore the downstream mechanisms mediating EMP1 regulation on cell viability and apoptosis in laryngeal carcinoma.

Cancer is composed of a heterogeneous population of cells, of which small parts present the capability of self-renewal and differentiation, mimicking normal stem cells, and thus are termed cancer stem cells. Colony formation assay is a method to measure the 'stemness' of the cancer cells (25). Cancer stem cells play critical and significant roles in the initiation, progression, metastasis, recurrence and drug resistance of cancer. Therefore, targeting these cells provides a promising strategy for cancer therapy (32). In this study, we showed for the first time that overexpressing EMP1 in laryngeal carcinoma cells reduced colony formation, suggesting that EMP1 may also regulate cancer stem cells in laryngeal carcinoma, which should be further evaluated using more comprehensive assays, both in vitro and in vivo, for cancer stem cells (33).

Migration is critical for local invasion as well as the distant metastasis of cancer cells. Consistent with multiple studies showing the effects of EMP1 in modulating cancer cell migration and/or invasion $(20,21,23,24,28)$ we showed that EMP1 expression in laryngeal carcinoma cells inhibited cell migration. 
In conclusion, previous studies showed that EMP1 may function either as a tumor suppressor or an oncoprotein, depending on the type of cancer. Here we reported tumor suppressor roles of EMP1 in laryngeal carcinoma. From 51 laryngeal carcinoma tissues, EMP1 does not seem to be a strong indicator for the progression or metastasis of laryngeal cancer, which may be limited by the small sample size and should be examined in future studies involving a greater number of samples. However, its pleotropic anticancer activities, specifically the newly identified effect of suppressing cancer stemness, together with membrane localization (thus allowing easy access for small molecules or other treatment reagents), present EMP1 as an ideal therapeutic target for laryngeal carcinoma. Although the molecular mechanisms underlying EMP1 activities should be further explored, it is expected that treatments that can stabilize or accumulate membrane EMP1 would benefit patients with laryngeal carcinoma.

\section{Acknowledgements}

We thank Chao Guan (Department of Genetics, Teaching and Learning Office, the First Affiliated Hospital of China Medical University) for his kind help with the biopsy screening and immunohistochemical experiment. We thank Yang Han and Liang Wang (Department of Pathology, the First Affiliated Hospital of China Medical University) for the staining score.

\section{References}

1. Wang W, Lin P, Han C, Cai W, Zhao X and Sun B: Vasculogenic mimicry contributes to lymph node metastasis of laryngeal squamous cell carcinoma. J Exp Clin Cancer Res 29: 60, 2010.

2. Lin HW and Bhattacharyya N: Staging and survival analysis for nonsquamous cell carcinomas of the larynx. Laryngoscope 118 1003-1013, 2008.

3. Marioni G, Marchese-Ragona R, Cartei G, Marchese F and Staffieri A: Current opinion in diagnosis and treatment of laryngeal carcinoma. Cancer Treat Rev 32: 504-515, 2006.

4. Choi P and Chen C: Genetic expression profiles and biologic pathway alterations in head and neck squamous cell carcinoma. Cancer 104: 1113-1128, 2005.

5. Liu YH, Tang PZ, Xu ZG, Qi YF, Ding F, Zhang LY, Wang HT and Liu ZH: Differential expression of the epithelial membrane protein 1 of laryngeal carcinoma. Zhongguo Yi Xue Ke Xue Yuan Xue Bao 25: 47-51, 2003 (In Chinese).

6. Zhang T, Wang Q, Zhao D, Cui Y, Cao B, Guo L and Lu SH: The oncogenetic role of microRNA-31 as a potential biomarker in oesophageal squamous cell carcinoma. Clin Sci (Lond) 121: 437-447, 2011.

7. Zhang J, Cao W, Xu Q and Chen WT: The expression of EMP1 is downregulated in oral squamous cell carcinoma and possibly associated with tumour metastasis. J Clin Pathol 64: 25-29, 2011.

8. Taylor V, Welcher AA, Program AE and Suter U: Epithelial membrane protein-1, peripheral myelin protein 22 , and lens membrane protein 20 define a novel gene family. J Biol Chem 270: 28824-28833, 1995.

9. Liehr T, Kuhlenbäumer G, Wulf P, Taylor V, Suter U, Van Broeckhoven C, Lupski JR, Claussen U and Rautenstrauss B: Regional localization of the human epithelial membrane protein genes 1, 2, and 3 (EMP1, EMP2, EMP3) to 12p12.3, 16p13.2, and 19q13.3. Genomics 58: 106-108, 1999.

10. Bredel M, Bredel C, Juric D, Harsh GR, Vogel H, Recht LD and Sikic BI: High-resolution genome-wide mapping of genetic alterations in human glial brain tumors. Cancer Res 65: 4088-4096, 2005.
11. Ben-Porath I and Benvenisty N: Characterization of a tumorassociated gene, a member of a novel family of genes encoding membrane glycoproteins. Gene 183: 69-75, 1996.

12. Lee HS, Sherley JL, Chen JJ, Chiu CC, Chiou LL, Liang JD, Yang PC, Huang GT and Sheu JC: EMP-1 is a junctional protein in a liver stem cell line and in the liver. Biochem Biophys Res Commun 334: 996-1003, 2005.

13. Taylor V and Suter U: Epithelial membrane protein-2 and epithelial membrane protein-3: Two novel members of the peripheral myelin protein 22 gene family. Gene 175: 115-120, 1996.

14. Jetten AM and Suter U: The peripheral myelin protein 22 and epithelial membrane protein family. Prog Nucleic Acid Res Mol Biol 64: 97-129, 2000.

15. Arslan AA, Gold LI, Mittal K, Suen TC, Belitskaya-Levy I, Tang MS and Toniolo P: Gene expression studies provide clues to the pathogenesis of uterine leiomyoma: New evidence and a systematic review. Hum Reprod 20: 852-863, 2005.

16. Lai S, Wang G, Cao X, Li Z, Hu J and Wang J: EMP-1 promotes tumorigenesis of NSCLC through PI3K/AKT pathway. J Huazhong Univ Sci Technolog Med Sci 32: 834-838, 2012.

17. Ariës IM, Jerchel IS, van den Dungen RE, van den Berk LC, Boer JM, Horstmann MA, Escherich G, Pieters R and den Boer ML: EMP1, a novel poor prognostic factor in pediatric leukemia regulates prednisolone resistance, cell proliferation, migration and adhesion. Leukemia 28: 1828-1837, 2014.

18. Zhang HT, Lu YC and He J: Expression of epithelial membrane protein 1 in human gliomas and its clinical implications. Chin $\mathrm{J}$ Cancer Biother 14: 466-470, 2007.

19. Wang HT, Kong JP, Ding F, Wang XQ, Wang MR, Liu LX, Wu M and Liu ZH: Analysis of gene expression profile induced by EMP-1 in esophageal cancer cells using cDNA microarray. World J Gastroenterol 9: 392-398, 2003.

20. Sun G, Zhao G, Lu Y, Wang Y and Yang C: Association of EMP1 with gastric carcinoma invasion, survival and prognosis. Int $\mathrm{J}$ Oncol 45: 1091-1098, 2014.

21. Sun GG, Wang YD, Cui DW, Cheng YJ and Hu WN: EMP1 regulates caspase-9 and VEGFC expression and suppresses prostate cancer cell proliferation and invasion. Tumour Biol 35: 3455-3462, 2014.

22. Cheong SC, Chandramouli GV, Saleh A, Zain RB, Lau SH, Sivakumaren S, Pathmanathan R, Prime SS, Teo SH, Patel V, et al: Gene expression in human oral squamous cell carcinoma is influenced by risk factor exposure. Oral Oncol 45: 712-719, 2009.

23. Sun GG, Wang YD, Lu YF and Hu WN: EMP1, a member of a new family of antiproliferative genes in breast carcinoma. Tumour Biol 35: 3347-3354, 2014.

24. Sun GG, Lu YF, Fu ZZ, Cheng YJ and Hu WN: EMP1 inhibits nasopharyngeal cancer cell growth and metastasis through induction apoptosis and angiogenesis. Tumour Biol 35: 3185-3193, 2014.

25. Franken NA, Rodermond HM, Stap J, Haveman J and van Bree C: Clonogenic assay of cells in vitro. Nat Protoc 1: 2315-2319, 2006.

26. Baccelli I and Trumpp A: The evolving concept of cancer and metastasis stem cells. J Cell Biol 198: 281-293, 2012.

27. Kuriakose MA, Chen WT, He ZM, Sikora AG, Zhang P, Zhang ZY, Qiu WL, Hsu DF, McMunn-Coffran C, Brown SM, et al: Selection and validation of differentially expressed genes in head and neck cancer. Cell Mol Life Sci 61: 1372-1383, 2004.

28. Sun GG, Wang YD, Cui DW, Cheng YJ and Hu WN: Epithelial membrane protein 1 negatively regulates cell growth and metastasis in colorectal carcinoma. World J Gastroenterol 20: 4001-4010, 2014

29. Kim MM and Califano JA: Molecular pathology of head-and-neck cancer. Int J Cancer 112: 545-553, 2004.

30. Wang HT, Liu ZH, Wang XQ and Wu M: Effect of EMP-1 gene on human esophageal cancer cell line. Ai Zheng 21: 229-232, 2002.

31. Li ZY, Xiong SH, Hu M and Hu M: Mitochondrial pathway is involved in the EMP1-induced apoptosis. Chin J Anat 31: 489-514, 2008.

32. Chen K, Huang YH and Chen JL: Understanding and targeting cancer stem cells: Therapeutic implications and challenges. Acta Pharmacol Sin 34: 732-740, 2013.

33. Stingl J: Detection and analysis of mammary gland stem cells. J Pathol 217: 229-241, 2009. 